\title{
EFEITO DO ÁCIDO GIBERÉLICO NA COMPOSIÇÃO DO ÓLEO ESSENCIAL DE Salvia officinallis $\mathbf{L}$.
}

\section{EFFECT OF GIBBERELLIC ACID ON THE COMPOSITION OF Salvia officinallis L. ESSENTIAL OIL}

\author{
Juliana Aparecida Povh ${ }^{1 *}$ Elizabeth Orika Ono $^{1}$ \\ 1* Autor para contato: Universidade Estadual Paulista Júlio de Mesquita Filho - UNESP, \\ Departamento de Botânica, Instituto de biociências, Botucatu, SP, Brasil; (14) 38116265 ; \\ e-mail:japovh@hotmail.com
}

Recebido para publicação em 13/09/2006

Aceito para publicação em 29/08/2007

\section{RESUMO}

Este estudo objetivou avaliar o efeito do ácido giberélico na composição do óleo essencial de plantas de Salvia offficinalis L. Para tanto, instalou-se o experimento em casa de vegetação, instalada no Departamento de Botânica, Instituto de Biociências, da Universidade Estadual Paulista, UNESP, Botucatu, SP. Odelineamento experimental foi inteiramente casualizado, com dois tratamentos contendo três repetições. Os tratamentos consistiram na aplicação do regulador vegetal: ácido giberélico $\left(\mathrm{GA}_{3}\right)$ a $100 \mathrm{mg} \mathrm{L}^{-1}$ e o controle (água). As aplicações foram realizadas em três épocas, aos 15, 25 e 35 dias após o transplante e o rendimento do óleo essencial foi avaliado aos 131 dias após o transplante. Para tanto, submeteu-se a parte aérea das plantas a secagem em estufa a $35^{\circ} \mathrm{C}$ e após a determinação de sua massa seca, procedeu-se à extração do óleo por hidrodestilação, determinando-se o seu volume. A composição desse óleo foi determinada por cromatógrafo gasoso acoplado a espectrometria de massa (CG/EM). Os resultados revelam que o ácido giberélico promoveu poucas alterações na composição química do óleo essencial, apresentando como principal efeito a redução significativa no teor de $\beta$-tujona e á-humuleno.

Palavras-chave: ácido giberélico, $\alpha$-humuleno, Salvia officinalis L., $\beta$-tujona

\begin{abstract}
This study aimed at evaluating the effect of gibberellic acid on the essential oil composition of Salvia officinalis L. plants. The experiment was installed in a greenhouse, at the Department of Botanics, Instituto de Biociências, of the Universidade Estadual Paulista, UNESP, Botucatu, SP, Brazil. The design was


completely randomized and consisted of two treatments with three replicates. The treatments consisted of the application of the plant regulator gibberellic acid $\left(\mathrm{GA}_{3}\right)$ at $100 \mathrm{mg} \mathrm{L}^{-1}$, and a control (water). The applications were performed at three time periods - 15, 25, and 35 days after transplanting - and the essential oil yield was evaluated 131 days after transplanting. The aerial part of the plants was dried in an oven at $35^{\circ} \mathrm{C}$ and after dry mass determination, the oil was extracted by hydrodistillation and its volume was determined. The oil composition was determined in a gas chromatograph attached to a mass spectrometer (GC/MS). In both treatments the results revealed that the substances that represent the highest contents in sage plants are á-thujone and camphor. The results also indicate that gibberellic acid produces few alterations on essential oil composition, but it promotes a significant decrease in $\beta$-tujone and $\alpha$-humulene contents.

Key words: gibberellic acid, $\alpha$-humulene, Salvia officinalis L., $\beta$-thujone

\section{Introdução}

Salvia officinalis L, pertencente à família Lamiaceae, é originária do mediterrâneo e aclimatada na região sul do Brasil. É considerada uma planta aromática e com propriedades medicinais, sendo usada como condimento e na medicina doméstica (Martins et al., 1998). A sálvia é uma planta medicinal muito popular que há décadas vem sendo estudada, devido aos seus componentes antioxidantes, sendo amplamente usada para tratamentos de vários grupos de doenças, preparação de alimentos, fabricação de cosméticos, perfumes e produtos de higiene (Chipault et al., 1952; Cuvelier et al., 1996).

O óleo essencial de sálvia é obtido principalmente das folhas, extraído por arraste de vapor com rendimento variando de 0,5 a $1,1 \%$. Possui como principais componentes a $\alpha$-tujona, cariofileno, 1,8-cineol, $\alpha$ humuleno e cânfora (Guillen et al., 1996). Os compostos presentes no óleo essencial são biologicamente ativos e possuem ação tóxica e farmacológica (Duke, 2002).

O valor comercial de plantas medicinais e aromáticas tem refletido qualitativa e quantitativamente na produção de seu óleo. O óleo é um produto do metabolismo da célula vegetal, sendo a composição não é estável e é dependente de diversos fatores que são regulados pelo metabolismo (Lawrence et al., 1971; Croteau e Karp, 1976).
O acúmulo do óleo essencial depende das fases de desenvolvimento da planta. A origem da folha primordial, sua expansão, total maturação e baixa senescência são importantes para a produção de óleo de valor comercial. A ontogenia também afeta a composição do óleo e, em Salvia officinalis L., o teor de cânfora aumenta com a expansão da folha (Croteau et al., 1981).

A utilização de reguladores vegetais pode modificar o comportamento de uma planta, alterando sua produtividade, como o seu metabolismo secundário, aumentando ou diminuindo o teor de óleo essencial e seus constituintes (Shukla e Faoroqi, 1990).

As giberelinas, pertencentes ao grupo dos hormônios vegetais, apresentam importantes papéis no crescimento vegetal, desenvolvimento e produtos secundários (Krishnamoorthy, 1979). São ativas na estimulação do alongamento celular (Stratford, 1978) e vários estudos têm demonstrado os efeitos do ácido giberélico (GA) aplicado em plantas medicinais e aromáticas no teor e composição do óleo essencial.

Outros estudos demonstram que o uso de giberelina em plantas medicinais e aromáticas promove diminuição na produção de óleo essencial e mudanças na composição (Trease e Evans, 1978).

A composição do óleo essencial de várias espécies de plantas medicinais e aromáticas tem sido de grande interesse econômico para indústrias farmacêuticas e na fabricação de perfumes e cosméticos. 
Possui também uma grande importância ecológica, uma vez que a variação na composição do óleo é extremamente dependente das características genéticas de cada espécie e das características ambientais.

Devido à escassez de estudos que relacione o uso de reguladores vegetais com a composição do óleo essencial de espécies medicinais e a aromáticas, o presente trabalho tem por objetivo estudar a composição do óleo essencial de Salvia officinalis L. sob a ação do ácido giberélico.

\section{Material e métodos}

$\mathrm{O}$ experimento foi conduzido entre agosto e dezembro de 2003 em casa de vegetação com controle de temperatura e umidade relativa do ar, instalada no Departamento de Botânica, Instituto de Biociências, da Universidade Estadual Paulista, UNESP, Botucatu, SP.

As plantas foram obtidas de sementes já tratadas com thiram (dissulfeto tetrametil - tiuram) previamente germinadas em câmara de germinação à temperatura de $25^{\circ} \mathrm{C}$ e luz constante. A seguir, as plântulas com 21 dias, foram transplantadas em vasos com capacidade de 4 litros, com terra corrigida e adubada. As plantas foram mantidas em casa de vegetação e irrigadas sempre que necessário. A temperatura máxima dentro da casa de vegetação durante a condução do experimento, foi $26^{\circ} \mathrm{C}$ e a mínima, $12^{\circ} \mathrm{C}$.

O experimento consistiu na aplicação de ácido giberélico na concentração de $100 \mathrm{mg} \mathrm{L}^{-1}$ comparado com plantas controle (água).

Foram realizadas três pulverizações via foliar, aos 15, 25 e 35 dias após o transplante, com pulverizador manual, adicionando-se espalhante adesivo não iônico (alquil-fenol-poliglicoléter), ou seja, o produto comercial Extravon na dose de $0,5 \mathrm{~mL} \mathrm{~L}^{-1}$ de solução, fabricado pela Ciba-Geigy Química S/A.

O ácido giberélico $\left(\mathrm{GA}_{3}\right)$ foi utilizado na forma do produto comercial Pro-Gibb contendo $10 \%$ de $\mathrm{GA}_{3}$, da Abbott Laboratórios do Brasil Ltda.

O delineamento experimental, inteiramente casualizado, consistiu de dois tratamentos, três repetições, em apenas uma época de colheita realizada aos 131 dias após o transplante (D.A.T.).
A massa fresca total da parte aérea das plantas, constituída por caules e folhas incluindo pecíolos, foi determinada em uma única época de colheita. Após a secagem em estufa de aeração forçada, à temperatura de $35^{\circ} \mathrm{C}$, até obtenção de massa seca constante determinou-se a massa seca total da parte aérea. A seguir, o material seco foi submetido a hidrodestilação, utilizando-se aparelho tipo Clevenger, durante duas horas para extração do óleo.

A composição química do óleo essencial foi analisada em cromatógrafo gasoso acoplado à espectrometria de massa (CG/EM), Shimadzu modelo QP-500 dotado de coluna capilar DB-5 $(30 \mathrm{mx} 0,25 \mathrm{~mm}$ $\mathrm{x} 0,25 \mu \mathrm{m}$ ), gás de arraste Hélio (fluxo $1,0 \mathrm{~mL} \cdot \mathrm{min}^{-1}$ ), injetor a $240^{\circ} \mathrm{C}$ e detector a $230^{\circ} \mathrm{C}$ na seguinte programação: $60^{\circ} \mathrm{C}$ - até $240^{\circ} \mathrm{C}, 3^{\circ} \mathrm{C}$ por minuto, split 1/20. Diluição de $2 \mathrm{mg}$ de óleo em $1 \mathrm{~mL}$ de acetato de etila; volume injetado de $1 \mu \mathrm{L}$. Para a identificação das substâncias, os espectros de massa foram comparados aos do banco de dados do sistema CG/EM (Nist. 62 Libr.) e literatura (McLafferty e Stauffer, 1989), determinando-se o índice de retenção de Kovats, comparando os mesmos com os citados na literatura (Adams, 1995).

Os resultados obtidos foram submetidos à análise de variância (teste F) para significância de 5\%.

\section{Resultados}

Os resultados da análise da composição do óleo essencial de plantas de Salvia officinalis L. podem ser observados na Tabela 1. Foram identificados no presente estudo seis compostos: 1,8-cineol, $\alpha$-tujona, $\beta$-tujona, cânfora, borneol e $\alpha$-humuleno.

De maneira geral, $\alpha$-tujona foi o composto encontrado em maior quantidade, enquanto que, borneol foi encontrado em menor quantidade nos dois tratamentos. Houve diferença significativa dos tratamentos sobre alguns componentes da composição do óleo essencial.

Em plantas tratadas com $\mathrm{GA}_{3}$ ocorreu pequeno aumento não significativo na quantidade de 1,8-cineol e borneol e redução não significativa para $\alpha$-tujona e cânfora. Promovendo ainda este regulador vegetal 
diminuição significativa para $\beta$-tujona $(\mathrm{F}<0,001)$ e $\alpha$ humuleno $(\mathrm{F}<0,0002)$ quando comparadas a plantas controle.

Tabela 1 - Composição do óleo essencial (\%) de plantas de Salvia officinalis L. sob ação do ácido giberélico.

\begin{tabular}{crr}
\hline Componentes & \multicolumn{2}{c}{ Tratamentos } \\
\hline (\%) & \multicolumn{1}{c}{ Controle } & $\mathbf{G A}_{\mathbf{3}} \mathbf{1 0 0} \mathbf{~ m g ~ L}^{-\mathbf{1}}$ \\
\hline 1,8-cineol & $4,71 \pm 0,19^{\mathrm{NS}}$ & $5,32 \pm 0,72$ \\
$\boldsymbol{\alpha}$-tujona & $24,82 \pm 1,75^{\mathrm{NS}}$ & $23,86 \pm 0,37$ \\
B-tujona & $14,06 \pm 1,67$ * & $5,91 \pm 0,67$ \\
Cânfora & $13,95 \pm 0,87^{\mathrm{NS}}$ & $13,08 \pm 0,92$ \\
Borneol & $2,38 \pm 0,55^{\mathrm{NS}}$ & $3,04 \pm 0,08$ \\
$\boldsymbol{\alpha}$-humuleno & $5,03 \pm 0,12^{*}$ & $2,24 \pm 0,37$
\end{tabular}

\pm Desvio Médio Padrão; *teste F a 5\% significância; ${ }^{\text {NS }}$ Não significativo.

\section{Agradecimentos}

Ao Conselho Nacional de Desenvolvimento Científico e Tecnológico $(\mathrm{CNPq})$ pelo apoio financeiro concedido para a execução deste trabalho.

\section{REFERÊNCIAS}

1. ADAMS, R.P. Identification of essential oil components by gas chromatography/mass spectroscopy. Carol Stream: Allured Publishing corporation, 1995.469p.

2. CHIPAULT, J.R.; MIZUNO, G.R.; HAWKINS, J.M.; LUNDBERG, W.O. The antioxidant properties of natural spices. Food Research, 17: 46-55, 1952.

3. CROTEAU. R.; FELTON, M.; KARP, F.; KJONAAS, R. relationship of camphor biosynthesis to leaf development in sage (Salvia officinalis). Plant Physiol., 67: 820-824, 1981.

4. CROTEAU. R.; KARP, F. Biosynthesis of monoterpenes: enzymatic conversion of nerly pyrophosphate to 1,8-cineole, á-terpienol, and cyclic monoterpene hydrocarbons by a cellfree preparation from sage (Salvia officinalis). Arch. of Biochem. Biophys., 176: 734-746, 1976.

5. CUVELIER, M.E.; RICHARD, H.; BERSET, C. Antioxidative activity and phenolic composition of pilot-plant and commercial extracts of sage and rosemary. J. Am. Oil Chem. Soc., 73: 645-652, 1996.

6. DUKE, J.A. Biologically: active compounds important spices. In: CHARALAMBOUS, G. Spices, herbs and edible fungi. Amsterdam: Elsevier Publishers, 1994. Egypt. J. Hortic., 27 : 459-478, 2002.

7. FUNK, C; KOEPP, A.E.; CROTEAU, R. Catabolism of camphor in tissue cultures and leaf disks of common sage (Salvia officinalis). Arch. Biochem. Biophys., 294: 306-313, 1992.

8. GUILLEN, M.D.; CABO, N.; BURILLO, J. Characterization of the essential oliz of some cultivated aromatic plants of industrial interest. J. Sci. Food Agric., 70: 359-363, 1996.

9. KRISHNAMOORTHY, H.N. Gibberellins and plant growth. New York: John Willy and sons, 1979. 563 p.

10. LAUWRENCE, B.M.; HOGG, J.W.; TERHUNE, S.J. Les huiles essentials et leurs constituents. IV. Quelques nouveaux constituents à I état de traces dans I'huile essentiale de Salvia officinalis L. Parfums Cosmet. Savons Fr., 1: 256-259, 1971.

11. MARTINS, E.R.; CASTRO, D.M.; CASTELLANI, D.C.; DIAS, J.E. Plantas medicinais. Viçosa: UFV, 1998. 220p.

12. MCLAFFERTY, F.W.; STAUFFER, D. The wiley/NBS registry os mass spectral data, New York: Wiley, 1989.v. 1-6.

13. SHUKLA, A.; FAROOQI, A.H.A.E. Review: utilization of plant growth regulators in aromatic plant production. Curr. Res. Med. Aromat. Plants, 12: 152-177, 1990.

14. STRATFORD, G.A. Essential of plant physiology "plant hormone". London: Heineman educational books Idt., 1978. $560 \mathrm{p}$.

15. TREASE, E.G.; EVANS, C.W. Pharmacognosy. 11. ed. London: Baillare Tindall, 1978, 812p. 